\title{
Efeitos da crise financeira de 2008 sobre o desemprego nas regiões metropolitanas brasileiras ${ }^{1}$
}

Fábio José Ferreira da Silva*

Fernando de Aquino Fonseca Neto ${ }^{* *}$

\section{Palavras-chave}

crise do subprime,

desemprego, Brasil

\section{Classificação JEL}

J20, J21

\section{Keywords}

subprime crisis, unemployment, Brazil

\section{JEL Classification}

J20, J21

\section{Resumo}

$\mathrm{O}$ artigo analisa os desdobramentos da crise do subprime sobre o desemprego nas regiões metropolitanas brasileiras pesquisadas pela Pesquisa Mensal do Emprego (PME/IBGE). A metodologia utilizada, de decomposição da variação do desemprego em contribuições da oferta e demanda por mão de obra, indica que os reflexos da crise não devem ser entendidos como brandos, como se poderia supor pela elevação aparentemente modesta da taxa de desemprego. Encontramos que a retração da demanda por mão de obra foi a mais intensa registrada com os dados da atual metodologia da pesquisa, que se inicia em março de 2002. A elevação do desemprego foi contida pela desaceleração da oferta de mão de obra, beneficiada pela menor pressão exercida pela PEA feminina. Setorialmente, a perda de postos de trabalho concentrou-se na indústria, sobretudo na indústria de transformação.

\section{Abstract}

The article analyzes the subprime crisis repercussions on unemployment in Brazilian metropolitan areas. We found that the effects were not as mild as one could suppose from the apparent modest increase in unemployment figures. Using the PME/IBGE data starting in March 2002, our results suggest that the contraction in labor demand has never been so intense, but the deceleration in labor supply, especially from women, contained the increase in unemployment. Among the sectors, job losses were concentrated in industry. 


\section{I_Introdução}

A crise financeira de 2008, que ficou conhecida como crise do subprime, originou-se no mercado hipotecário de alto risco norte-americano, alastrando-se pelo mundo de maneira intensa e veloz, resultando em uma crise global, com efeitos expressivos na economia real. Considerada a pior crise desde a Grande Depressão, foi tema de diversos artigos, vide Stiglitz (2008, 2009), Krugman (2009), Eichengreen (2009), Reinhart e Rogoff (2009). Em diversos países, especialmente nos desenvolvidos, a gravidade da crise no mercado de trabalho pode ser vista não apenas pela elevação da taxa de desemprego, como também pelo aumento da participação de formas vulneráveis de emprego, estagnação do crescimento da produtividade da mão de obra e aumento do desalento, especialmente da população jovem (International Labour Office, 2011).

No Brasil, o mercado de trabalho passava por um momento favorável quando foi atingido pela crise, como se verifica pela taxa de desemprego, que se encontrava em $7,8 \%$ na média do terceiro trimestre de 2008 - naquele período, o nível mais baixo desde o início da série calculada com a metodologia atual, iniciada em março de 2002, de acordo com a Pesquisa Mensal do Emprego do Instituto Brasileiro de Geografia e Estatística (PME/IBGE). A mudança de percurso imposta pela crise ao desemprego no Brasil é o objeto de análise deste artigo, juntando-se a outros, ainda pouco numerosos, que abordam o tema. Um dos primeiros foi Pochmann (2009), que, enfatizando o período que vai de outubro de 2008 a março de 2009, encontra evidências de deterioração das condições do mercado de trabalho, como o aumento da informalidade e da rotatividade nos empregos assalariados formais.

Cacciamali e Tattei (2010) comparam a evolução de indicadores do mercado de trabalho da crise de 2008-2009 com a fase 1997-1998 (crises da Ásia e da Rússia). Os resultados mostram que a taxa de inatividade aumentou nos dois períodos para indivíduos menos escolarizados; porém, a intensidade foi maior na crise de 2008-2009, sobretudo para aqueles com fundamental completo. Nos dois períodos, no imediato pós-crise, a taxa de ocupação diminuiu para todos os níveis de escolaridade, mas a queda foi maior para os menos escolarizados.

Moretto e Proni (2011) relacionam os impactos menores da crise do subprime no Brasil em comparação a outros países às políticas anticíclicas adotadas pelo governo, que privilegiaram a manutenção da demanda, garantindo o nível de atividade e do emprego. Citam-se, na área monetária, a redução das taxas de juros, medidas para equilibrar a liquidez e o aumento da oferta de crédito dos bancos públicos. $\mathrm{Na}$ esfera fiscal, houve desoneração tributária, ampliação dos investimentos em infraestrutura e das transferências aos programas sociais.

O perfil dos demitidos é investigado em Silva (2012). Por meio de um modelo de transição, que diferencia os demitidos da crise daqueles não demitidos do setor industrial, identifica características pessoais e dos postos de trabalho associados a maior probabilidade de demissão para o período compreendido entre setembro de 2008 e julho de 2009. Trabalhadores informais, subocupados, com menos tempo de serviço e menor rendimento, tiveram maiores chance de demissão. Acerca das características pessoais, as demissões foram maiores nos extremos da escala de idade - jovens e velhos - em comparação aos adultos; menores níveis de escolaridade aumentaram a probabilidade de demissão; mulheres foram mais atingidas que homens.

O presente artigo inova na metodologia, que realiza a decomposição da variação da taxa de desemprego em dois componentes que podem representar alterações da oferta e da demanda por mão de obra. O efeito demanda por mão de obra mede o impacto do ajuste dos empregadores, ou seja, das 
demissões e redução das contratações. A componente oferta de mão de obra - que reflete as variações da população economicamente ativa - é influenciada, sobretudo, por fatores demográficos, que têm sofrido alterações importantes no Brasil, mas que não estão relacionadas diretamente com a crise.

Na próxima seção, são descritos os desdobramentos da crise sobre a atividade econômica e ocupação, nas regiões metropolitanas e não metropolitanas. Na seção III, a evolução da taxa de desemprego nas regiões metropolitanas do Brasil é comparada a de outros países, desenvolvidos e emergentes. Observa-se que, nos países desenvolvidos, a crise do subprime repercutiu de forma mais profunda e permanente. No Brasil, os efeitos adversos sobre o mercado de trabalho duraram apenas cinco meses, e, após essa fase, a trajetória de queda do desemprego foi restabelecida. Ainda que tenha se dissipado rapidamente, enquanto atuante, a crise do subprime teve impactos agudos no país.

A metodologia de decomposição do desemprego é desenvolvida na seção IV, cujos resultados, apresentados na seção V, mostram que a demanda por mão de obra recuou no período, traduzindo a destruição líquida de postos de trabalho. Comparando com outras duas fases de aumento do desemprego verificadas entre 2002 e 2010, encontra-se que a crise do subprime foi a mais severa para a população ocupada. Setorialmente, as demissões concentraram-se na indústria, principalmente nos segmentos de metalurgia básica, produtos de metal e fabricação de equipamentos, que perderam mais de $10 \%$ de seus postos de trabalho. Destaca-se ainda que a desaceleração da oferta de mão de obra - influenciada pela redução do crescimento da PEA feminina em comparação ao registrado na primeira metade da década, e, portanto, independente da própria crise - contribuiu para conter o aumento do desemprego. As principais conclusões do artigo são enunciadas na seção VI.

\section{2_Mercado de trabalho nas regiões metropolitanas e não metropolitanas do Brasil durante a crise}

Ao analisar o comportamento da taxa de desemprego do Brasil, o presente artigo restringe-se à cobertura geográfica do indicador, que corresponde às Regiões Metropolitanas do Recife, de Salvador, de Belo Horizonte, do Rio de Janeiro, de São Paulo e de Porto Alegre. Visando identificar os efeitos da crise de forma mais abrangente, ${ }^{2}$ relaciona-se à evolução da atividade econômica e do mercado de trabalho, comparando dados metropolitanos e não metropolitanos.

Utiliza-se, como proxy para a ocupação, o Índice do Nível de Emprego Formal (INEF), conforme metodologia do Banco Central do Brasil descrita no Anexo 1. O indicador, que mede a criação de vínculos formais, a exemplo do INEF nacional (série disponível no site da instituição), foi construído para duas regiões: conjunto das regiões metropolitanas (INEF metropolitano) e demais regiões do país (INEF nãometropolitano). A fonte de dados do INEF é o Ministério do Trabalho e Emprego (MTE) e, do PIB, o Instituto Brasileiro de Geografia e Estatística (IBGE). Todas as séries foram dessazonalizadas.

Conforme se verifica na Tabela 1, os efeitos da crise do subprime sobre a economia brasileira manifestaram-se por dois trimestres consecutivos, a partir do quarto trimestre de 2008. O crescimento do PIB, de 1,6\% assinalado no terceiro trimestre de 2008 em relação ao trimestre anterior, foi sucedido por recuos de $3,9 \%$ e 1,6\%. No terceiro trimestre de 2009, houve crescimento de 1,5\%, acelerando-se nos períodos subsequentes. O INEF nacional, de maneira geral, acompanhou a tendência do PIB, desacelerando-se na passagem do terceiro para o quarto trimestre de 2008, de 1,8\% para $0,5 \%$. O primeiro trimestre de 2009 representou a fase mais aguda dos efeitos da crise sobre o mercado formal, com demissões líquidas de 0,6\% do total de empregados.

Não existem dados de PIB metropolitanos e não metropolitanos em bases trimestrais, ${ }^{3}$ mas a segregação do 
INEF - em INEF metropolitano e não metropolitano - sugere que as regiões metropolitanas foram comparativamente menos afetadas do que as não metropolitanas. A princípio, do terceiro para o quarto trimestre de 2008, o INEF metropolitano passou de $1,3 \%$ para $0,5 \%$, ao passo que o não metropolitano, de $1,3 \%$ para $0,3 \%$. No primeiro trimestre de 2009 , fase mais aguda da crise, o INEF metropolitano caiu $0,1 \%$, e o não metropolitano apresentou queda de $0,6 \%$.

Tabela 1_Indicadores de atividade econômica e do emprego formal. Variação percentual em relação ao trimestre anterior.

Dados dessazonalizados

\begin{tabular}{|c|c|c|c|c|c|}
\hline Indicador & Ano & $\begin{array}{l}1^{0} \\
\text { Trimestre }\end{array}$ & $\begin{array}{l}2^{\circ} \\
\text { Trimestre }\end{array}$ & $\begin{array}{l}3^{\circ} \\
\text { Trimestre }\end{array}$ & $\begin{array}{l}4^{\circ} \\
\text { Trimestre }\end{array}$ \\
\hline \multirow{2}{*}{$\begin{array}{l}\text { PIB } \\
\text { Brasil }\end{array}$} & 2008 & 1,8 & 1,5 & 1,6 & $-3,9$ \\
\hline & 2009 & $-1,6$ & 1,5 & 2,6 & 2,7 \\
\hline \multirow{2}{*}{$\begin{array}{l}\text { NIEF } \\
\text { Brasil }\end{array}$} & 2008 & 1,8 & 1,7 & 1,8 & 0,5 \\
\hline & 2009 & $-0,6$ & 0,1 & 1,0 & 1,8 \\
\hline \multirow{2}{*}{$\begin{array}{l}\text { NIEF } \\
\text { Metropolitano }\end{array}$} & 2008 & 1,5 & 1,4 & 1,3 & 0,5 \\
\hline & 2009 & $-0,1$ & 0,2 & 0,8 & 1,2 \\
\hline \multirow{2}{*}{$\begin{array}{l}\text { NIEF } \\
\text { Não } \\
\text { metropolitano }\end{array}$} & 2008 & 1,2 & 1,1 & 1,3 & 0,3 \\
\hline & 2009 & $-0,6$ & 0,0 & 0,7 & 1,4 \\
\hline
\end{tabular}

Fonte: IBGE (dados do PIB) e INEF (MTE).

$O$ resultado de que o mercado de trabalho metropolitano foi mais resistente à crise em comparação ao da região não metropolitana deve ser visto com cautela. Em primeiro lugar, o INEF desconsidera a evolução do mercado informal, que é expressivo no país e que pode ter evoluído de forma distinta nas regiões metropolitanas vis-à-vis não metropolitanas. Além disso, funcionários públicos estatutários, que têm estabilidade por força de lei, não fazem parte da série. Levando em consideração que esse segmento tem maior peso na região não metropolitana - correspondem a 21,1\% do total de empregados formais de acordo com a Relação Anual de Informações Sociais (RAIS) do MTE relativa a 2011, em comparação a 17,1\% da região metropolitana -, esse fator contribuiria para aproximar, ao menos em parte, a evolução do emprego das regiões durante a crise.

\section{3_Evolução comparativa internacional do desemprego}

As taxas de desemprego das principais economias mundiais estavam em níveis baixos antes dos efeitos da crise. Nos países desenvolvidos - representados, no Gráfico 1, pelos EUA e pelos países que compõem a área do Euro - o indicador vinha caindo até o final de 2007, quando inverteu a tendência até atingir cerca de $10 \%$ no final de 2009, de acordo com dados dessazonalizados. Nesses casos, o choque foi profundo e duradouro.

Nos países emergentes, a crise chegou com defasagem e as elevações do desemprego ${ }^{4}$ foram inferiores às dos países desenvolvidos. Na Rússia, a crise começou a afetar o mercado de trabalho no segundo trimestre de 2008, e, no México e no Brasil, os reflexos só foram sentidos no segundo semestre. Além disso, nota-se que, nesses três países, 0 desemprego já começou a recuar no segundo semestre de 2009. No Brasil, ao final de 2009, a taxa de desemprego havia recuperado o patamar de $8,0 \%$ verificado antes dos efeitos da crise. A taxa de desemprego na China foi a menos atingida, elevando-se em 0,3 p.p. do terceiro para o quarto trimestre de 2008, chegando a 4,3\%.

De acordo com o International Labour Office (2010), as heterogeneidades verificadas dos efeitos da crise no mercado de trabalho mundial decorreram de três razões principais:

(i) Situação do sistema financeiro doméstico antes da crise. Países onde o sistema se envolveu em operações de alto risco (como os derivativos complexos que abrangem títulos do mercado imobiliário) foram mais expostos à restrição ao crédito, comprometendo o fluxo de recursos ao setor privado; 
(ii) Solidez fiscal. Países que entraram na crise com maior equilíbrio fiscal tiveram condições de implementar pacotes contracíclicos e medidas de estímulo, em contraste a outros que tiveram menores condições de reação;

(iii) Intensidade do impacto externo. Sofreram mais as economias mais endividadas no mercado internacional, onde o setor exportador tem maior participação no PIB e no emprego, os investimentos externos são mais relevantes.

Analisando 84 países, o International Labour Office (2010) enquadra o Brasil no grupo onde os efeitos sobre o desemprego foram considerados de leve a moderado.

Gráfico 1_Comparativo internacional das taxas de desemprego (\%)

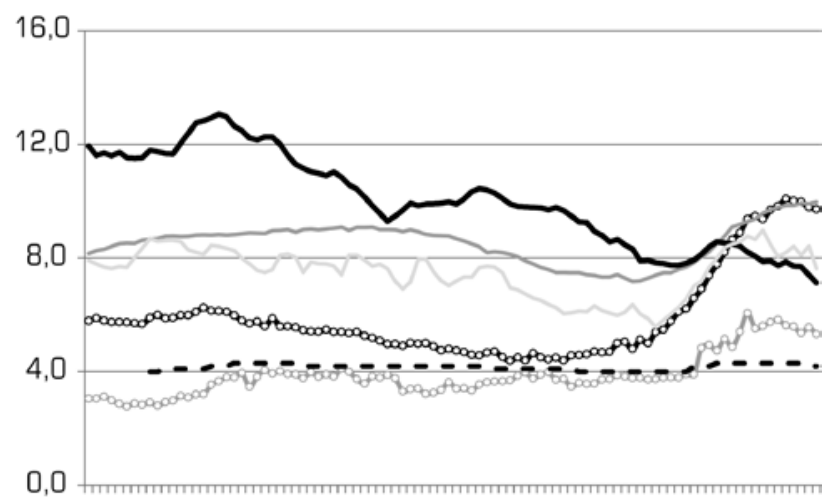

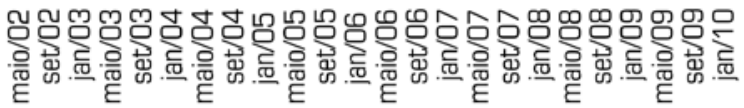

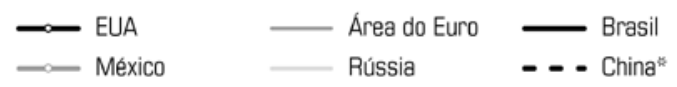

Fonte: IBGE e Bloomberg. Dados dessazonalizados.

* Série com dados trimestrais, não dessazonalizados, iniciada no quarto trimestre de 2002.

\section{4_Fases de ascensão do desemprego no Brasil}

De maio de 2002 a junho de 2010, de maneira geral, a taxa de desemprego do país apresentou tendência de queda, excetuando-se três períodos, resumidos na Tabela 2. As fases de elevação do desemprego foram delimitadas da seguinte forma: iniciam-se quando o desemprego aumenta e terminam quando o desemprego cai por pelo menos três meses consecutivos, ainda que reconheçamos a arbitrariedade do critério.

\section{Gráfico 2_Taxa de desemprego [\%]}

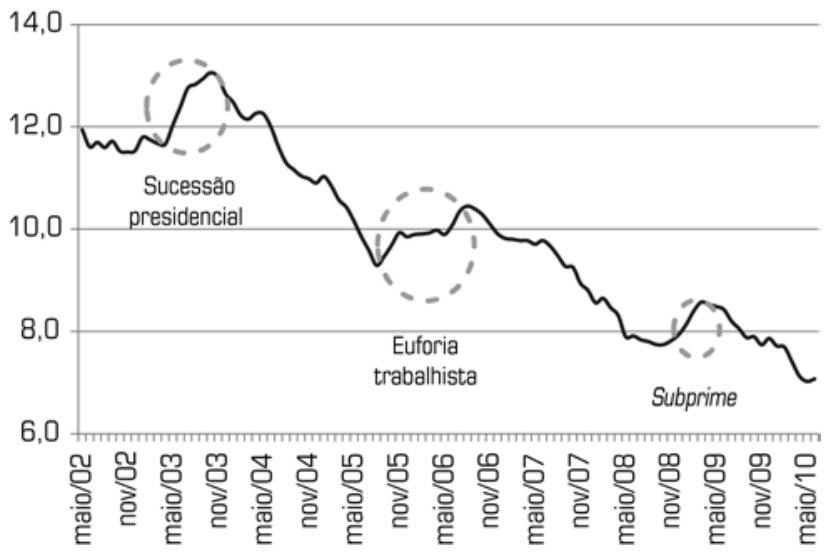

Fonte: PME/IBGE.

Tabela 2_Fases de aumento do desemprego

\begin{tabular}{l|r|l|r|r} 
& $\begin{array}{l}\text { Sucessão } \\
\text { presidencial }\end{array}$ & $\begin{array}{l}\text { Euforia } \\
\text { trabalhista }\end{array}$ & $\begin{array}{l}\text { Crise do } \\
\text { subprime }\end{array}$ \\
\hline Início do período & maio/03 & set/05 & nov/08 \\
\hline Final do período & out/03 & ago/06 & mar/09 \\
\hline Duração em meses & 6 & 12 & 5 \\
\hline Desemprego no início (\%) & 11,7 & 9,3 & 7,7 \\
\hline Desemprego no final (\%) & 13,1 & 10,4 & 8,6 \\
\hline Variação (p.p.) & 1,4 & $\ldots, 2$ & $\ldots, 8$ \\
\hline
\end{tabular}

Fonte: Elaboração dos autores com os dados da PME/IBGE. 
O primeiro período, que denominamos de "sucessão presidencial", refletiu a turbulência associada ao período de transição do governo de FHC para o de Lula. As incertezas relacionadas ao novo governo levaram a uma forte saída de capitais, desvalorização cambial e elevação da inflação, que exigiram medidas de austeridade monetária e fiscal, que, em um primeiro momento, tiveram impacto recessivo.

$\mathrm{Na}$ segunda fase, que denominamos de "euforia trabalhista", o aumento do desemprego medido pela PME/IBGE resultou de uma pressão exercida pela oferta de mão de obra, possivelmente em razão de fatores relacionados à conjuntura favorável. $\mathrm{O}$ estímulo pode ter sido proporcionado pelo aumento das contratações e dos salários em meses anteriores, conforme descrito em Banco Central do Brasil (2006):

\section{"[...] o comportamento da taxa de desemprego em períodos recentes está associado, fundamentalmente, a fatores conjunturais, conforme sugerem, por exemplo, as taxas de crescimento da massa salarial real, de 4,2\% em 2005 e de 6,2\% nos primeiros meses de 2006 [...]"}

e ainda

"[...] essa hipótese é fortalecida pelas estatísticas da Pesquisa de Emprego e Desemprego (PED)

[...] evidenciam que a diminuição do desemprego oculto vem impactando a PEA, e, em consequência, a proporção de desocupados e a taxa de desemprego [...]".

Como primeira observação, percebe-se na Tabela 2 que a crise do subprime teve a menor duração (5 meses) e intensidade (aumento de 0,8 p.p. da taxa de desemprego) em comparação aos outros períodos. Para compreender melhor as diferenças entre os três períodos, realiza-se, em seguida, uma decomposição da variação da taxa de desemprego.

\section{5_Metodologia de decomposição do desemprego}

Inicialmente, são estabelecidas as seguintes definições:

$$
\begin{aligned}
& u=\frac{P E A_{t}-P O_{t}}{P E A_{t}} \\
& o_{t}=\frac{P O_{t}}{P E A_{t}} \\
& s=\frac{P E A_{t}}{P E A_{t-1}} \\
& d=\frac{P O_{t}}{P O_{t-1}}
\end{aligned}
$$

Onde $u$ é a taxa de desemprego, $o$ é a ocupação, $s$ e $d$ representam as taxas de crescimento da população economicamente ativa (PEA) e da população ocupada (PO).

Dessa forma, a variação do desemprego é dada por:

$$
\Delta u=o_{t-1}\left(\frac{s-d}{s}\right)
$$

Conforme Banco Central do Brasil (2010), pode-se realizar um exercício em que a equação (5) é decomposta em três componentes, expressos em pontos percentuais (p.p.):

(i) efeito oferta de mão de obra $\left(\Delta \mathrm{u}_{\mathrm{s}}\right)$, compreendido como o impacto exercido sobre a taxa de desemprego pela variação da PEA, mantida a PO constante. Quando positivo, o efeito mede os 
indivíduos que se incorporaram ao mercado de trabalho, podendo representar o comportamento da oferta de mão de obra;

$\Delta u_{s}=o_{t-1}\left(\frac{s-1}{s}\right)$

(ii) efeito demanda por mão de obra $\left(\Delta u_{\mathrm{d}}\right)$, definido como a contribuição para a variação da taxa de desemprego decorrente de alterações na PO, com a PEA inalterada. Ele capta os desempregados que procuravam (em $t$ - 1 ) e encontraram ocupação (em $t$ ). Pelo fato de isolar a contribuição do crescimento da população ocupada, esse efeito pode representar o comportamento da demanda por mão de obra;

$$
\Delta u_{d}=o_{t-1}(d-1)
$$

(iii) efeito residual $\left(\Delta u_{r}\right)$ : é composto de um efeito cruzado da PEA com a PO. Em análises de curto prazo, como a desenvolvida neste artigo, o componente tende a zero, de modo que nos limitaremos a apresentá-lo nos resultados, dispensando considerações adicionais.

$$
\Delta u_{r}=o_{t-1}\left(\frac{s d-s-d+1}{s}\right)
$$

Pode-se notar facilmente que:

$$
\Delta u=\Delta u_{s}-\Delta u_{d}+\Delta u_{r}
$$

\section{6_Resultados da decomposição do desemprego e desdobramentos}

Os resultados são apresentados na Tabela 3. Tendo em vista que o número de meses das fases não é igual, apresentam-se, entre colchetes, as contribuições anualizadas (p.p.a.a.) para facilitar as comparações. Consta-se que a elevação do desemprego ocorreu por razões distintas. Em primeiro lugar, analisa-se o efeito oferta de mão de obra, que contribuiu com 1,7 p.p. (3,3 p.p.a.a.) para o aumento do desemprego durante a sucessão presidencial, passando a 2,7 p.p. (2,7 p.p.a.a.) na época da euforia trabalhista e 0,4 p.p. $(1,0$ p.p.a.a.) na crise do subprime.

\begin{tabular}{|c|c|c|c|}
\hline Fases & $\begin{array}{l}\text { Sucessão } \\
\text { presidencial }\end{array}$ & $\begin{array}{l}\text { Euforia } \\
\text { trabalhista }\end{array}$ & $\begin{array}{l}\text { Crise do } \\
\text { subprime }\end{array}$ \\
\hline $\begin{array}{l}\text { Variação do desemprego } \\
(\Delta u)\end{array}$ & 1,4 [2,8] & $1,2[1,2]$ & 0,8 [2,0] \\
\hline $\begin{array}{l}\text { Efeito oferta de } \\
\text { mão de obra }\left(\Delta \mathrm{u}_{\mathrm{s}}\right)\end{array}$ & 1,7 [3,3] & 2,7 [2,7] & $0,4[1,0]$ \\
\hline $\begin{array}{l}\text { Efeito demanda por } \\
\text { mão de obra }\left(\Delta u_{\mathrm{d}}\right)\end{array}$ & $0,3[0,6]$ & $1,6[1,6]$ & $-0,4[-1,0]$ \\
\hline Efeito residual $\left(\Delta u_{r}\right)$ & $0,01[0,02]$ & $0,05[0,05]$ & $0,00[-0,01]$ \\
\hline
\end{tabular}

Tabela 3_Decomposição da variação do desemprego Em pontos percentuais

Nota: Valores entre colchetes são expressos em pontos percentuais ao ano (p.p.a.a.).

Fonte: Elaboração dos autores com os dados da PME/IBGE.

A redução do efeito oferta de mão de obra na crise do subprime resulta da desaceleração verificada na PEA, e uma das causas desse resultado é que a forte entrada de mulheres no mercado de trabalho vem, paulatinamente, reduzindo de intensidade. É possível ilustrar o argumento, compa- 
rando a evolução da PEA masculina e feminina, estimada com a inclusão de uma tendência quadrática:

$$
\ln (\widehat{P E A})=\beta_{0}+\beta_{1} t+\beta_{2} t^{2}
$$

Tabela 4_Evolução da PEA

\begin{tabular}{|c|c|c|}
\hline Parâmetros & PEA masculina & PEA feminina \\
\hline$\beta_{0}$ & 9,33 & 9,09 \\
\hline$\beta_{1}$ & $1,68\left(10^{-3}\right)$ & $2,98\left(10^{-3}\right]$ \\
\hline$\beta_{2}$ & $-6,16\left(10^{-6}\right)$ & $-9,86\left(10^{-6}\right)$ \\
\hline$R^{2}$ & $96 \%$ & $96 \%$ \\
\hline
\end{tabular}

Nota: Todos os coeficientes são significantes a $1 \%$.

Fonte: Elaboração dos autores com os dados da PME/IBGE.

A Tabela 4 mostra que as PEAs masculina e feminina podem ser ajustadas por funções convexas, em que $\beta_{1}>0 \mathrm{e} \beta_{2}<0$. Destaca-se, inicialmente, que o coeficiente $\beta_{1}$ feminino é substancialmente maior que o masculino, ${ }^{5}$ refletindo o maior crescimento da PEA feminina, sobretudo nos períodos iniciais da série. Na crise da sucessão presidencial, por exemplo, a taxa de crescimento da PEA feminina, em termos anualizados, foi de 5,9\%, contra 2,5\% da masculina. Para Hoffman e Leone (2004), a mudança do perfil do mercado de trabalho, com o aumento da participação feminina, verifica-se desde o início dos anos 80, refletindo a maior presença de mulheres como chefes de família e a permanência de cônjuges com filhos no mercado de trabalho. Esse aumento, que começou com as mulheres de melhor nível socioeconômico, vem se difundindo para níveis mais baixos. Leone e Baltar (2008) mostram que o emprego em estabelecimentos, isto é, excetuando-se o emprego doméstico, tem crescido mais para mulheres do que para os homens, o que, segundo Ramos (2009), poderia estar relacionado ao abran- damento de posturas discriminatórias e segregacionistas. Tal processo pode ser entendido como uma transição estrutural da participação feminina no mercado de trabalho.

Em segundo lugar, nota-se que a desaceleração na PEA feminina é mais acentuada que a da PEA masculina (em módulo $\beta_{2}$ fem $>\beta_{2}$ masc), repercutindo uma moderação do processo de aumento de participação de mulheres no mercado de trabalho, ou seja, os resultados sugerem redução das disparidades observadas entre as taxas de crescimento das PEAs masculina e feminina ao longo do tempo. Na crise do subprime, a taxa anual de crescimento da PEA feminina foi de $1,0 \%$, superando a masculina em 0,3 p.p.

Tabela 5_Comparativo das taxas de crescimento anuais da PEA, por gênero

\begin{tabular}{|c|c|c|c|}
\hline Fases & $\begin{array}{l}\text { Sucessão } \\
\text { presidencial }\end{array}$ & $\begin{array}{l}\text { Euforia } \\
\text { trabalhista }\end{array}$ & Subprime \\
\hline PEA & 3,9 & 3,1 & 1,1 \\
\hline PEA masculina & 2,5 & 2,5 & 1,0 \\
\hline PEA feminina & 5,9 & 3,7 & 1,3 \\
\hline
\end{tabular}

Fonte: Elaboração dos autores com os dados da PME/IBGE.

A conclusão geral acerca da oferta de mão de obra é que uma das razões para a menor elevação do desemprego na crise decorre de uma desaceleração do crescimento dessa oferta, refletindo menor pressão exercida pela PEA feminina, tendência que se encontrava em curso, independentemente da crise. ${ }^{6}$ Se fixássemos a PO durante a crise, deixando a PEA crescer à mesma taxa do período de sucessão presidencial e da fase da euforia trabalhista, encontraríamos que, em vez de 8,6\%, o desemprego teria se elevado respectivamente para 9,6\% e 9,3\%.

Em relação ao efeito demanda por mão de obra, verifica-se que a crise do subprime foi a única, entre as três analisadas, com valor negativo, ou seja, contribuiu em 0,4 p.p. (1,0 p.p.a.a.) para o aumento do desemprego. Isso quer dizer 
que apenas nesse caso houve destruição líquida de postos de trabalho, evidenciando que a crise não foi tão suave como se poderia inferir pela alta aparentemente modesta da taxa de desemprego. Na sucessão presidencial e na fase de euforia trabalhista, o desemprego se elevou porque o aumento da demanda por mão de obra foi insuficiente para fazer frente ao aumento da oferta, enquanto, na crise do subprime, a demanda por mão de obra efetivamente se reduziu. Em síntese, comparando os períodos de aumento do desemprego, pode-se concluir que a crise do subprime foi a mais severa no que se refere à demanda por mão de obra e que o aumento do desemprego - aparentemente pequeno em relação aos outros períodos - só não foi maior porque a desaceleração da oferta de mão de obra foi mais acentuada.

Por último, é valioso investigar como a crise afetou a população ocupada pelos seguintes setores: (i) indústria; ${ }^{7}$ (ii) construção civil; (iii) comércio; (iv) outros serviços. Conforme nos referimos anteriormente, definimos o efeito da crise do subprime como o período de ascensão da taxa de desemprego geral, compreendido entre os meses de novembro de 2008 e março de 2009. O Gráfico 3 mostra que, de janeiro de 2008 até o início da crise, a construção civil e a indústria eram os setores com as maiores taxas de crescimento das ocupações. Com a crise, a situação se inverteu, e esses passaram a ser os setores mais afetados, sobretudo a indústria, que se retraiu em 1,9\% até março. Ressalte-se ainda que, por mais que, a partir de abril de 2009, a ocupação tenha crescido em termos agregados, a indústria seguiu em retração contínua por mais quatro meses, chegando a perder 4,3\% dos postos de trabalho. Na construção civil, a crise reduziu os postos de trabalho em 1,5\%, mas em agosto a ocupação já havia recuperado o patamar pré-crise. Por outro lado, pode-se dizer que os setores de comércio e outros serviços praticamente não foram afetados por uma crise, haja vista que a geração líquida de postos de trabalho
Gráfico 3_Ocupação dos setores na crise do Subprime

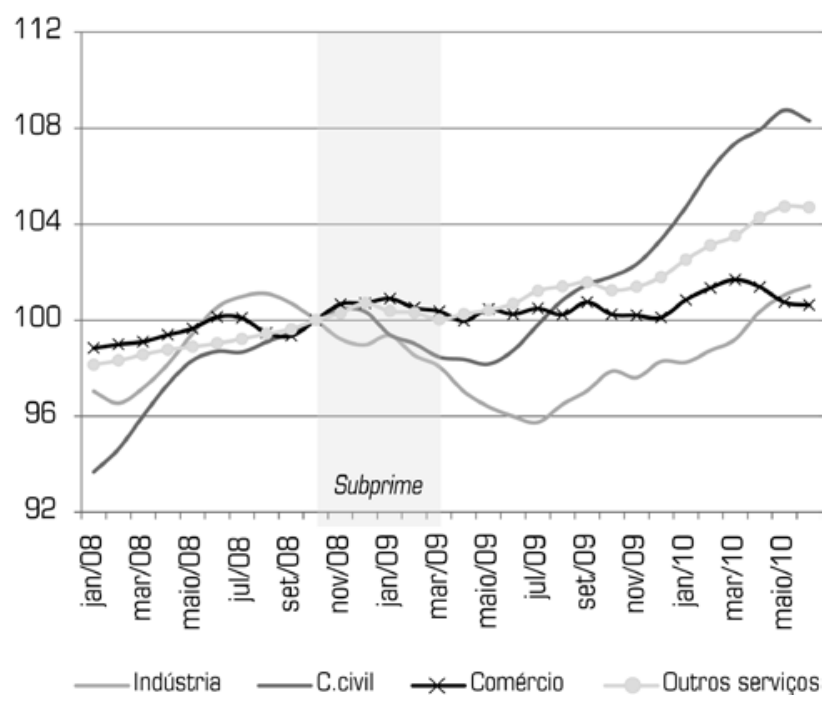

Fonte: PME/IBGE. Dados dessazonalizados. Outubro de $2008=100$.

cresceu $0,4 \%$ no setor de comércio e permaneceu estável nos demais serviços.

Em valores absolutos, a perda de empregos da indústria totalizou 154,2 mil postos de trabalho até julho de 2009, dos quais 159,0 mil foram na indústria de transformação, parcialmente compensada pelos 2,8 mil empregos na indústria extrativa e pelos 2,0 mil em nos SIUP, como se observa no Anexo 2. Em termos percentuais, o setor mais atingido foi o de metalurgia básica, que eliminou $18,7 \%$ dos trabalhadores, seguido por produtos de metal, 14,8\% e "fabricação de equipamentos de instrumentação médico-hospitalares, instrumento de precisão e ópticos, equipamentos para automação industrial", com 12,4\%.

\section{7_Conclusão}

Os desdobramentos da crise sobre o desemprego no Brasil foram menos intensos e de menor duração em com- 
paração com diversos países, sobretudo os desenvolvidos. Contudo, nossos resultados evidenciam que seus efeitos não foram brandos, como se poderia supor pela elevação aparentemente modesta da taxa de desemprego, para 8,6\%. Pelo contrário, comparando com outros períodos de aumento do desemprego, a crise do subprime foi mais severa no que se refere à demanda por mão de obra, com destruição líquida de postos de trabalho. $\mathrm{O}$ aumento do desemprego foi contido pela menor pressão exercida pela PEA feminina, o que aparentemente independe da própria crise. Ao longo dos anos analisados, a oferta de mão de obra feminina cresceu sistematicamente acima da masculina, porém essa diferença tem se reduzido gradativamente. Se não fosse por esse efeito do lado da oferta de mão de obra, o desemprego, em vez de $8,6 \%$, poderia ter subido para níveis próximos a 9,6\% no horizonte de cinco meses, conforme apuramos em simulações.

Analisando setorialmente os desdobramentos da crise sobre a ocupação, encontramos que os setores de comércio e os demais serviços passaram ao largo da crise. A construção civil foi moderadamente impactada pela crise, mas sem dúvida a perda de postos de trabalho concentrou-se na indústria, onde essa perdurou por 10 meses, destacando-se "Metalurgia básica", "Produtos de metal","Fabricação de equipamentos de instrumentação médico-hospitalares, instrumento de precisão e ópticos, equipamentos para automação industrial" e "Preparação de couro e calçados", com perdas da população ocupada superiores a 10\%. Possivelmente, esses setores são compostos de empresas exportadores e/ou que possuem algum tipo de restrição ao crédito, já que esses foram canais de transmissão importantes da crise financeira internacional para o Brasil.

\section{Notas}

${ }^{1}$ As opiniões expressas neste artigo são de inteira

responsabilidade dos autores e não refletem, necessariamente, a opinião do Banco Central do Brasil.

${ }^{2}$ Os autores agradecem a um parecerista anônimo, que sugeriu a abordagem regionalizada desenvolvida nessa seção.

${ }^{3}$ Os dados de PIB municipal são anuais e deve-se considerar que tal periodicidade não é adequada para se analisar a crise, cujos efeitos foram distribuídos em 2008 e 2009. O PIB de 2009, por exemplo, resulta de um primeiro semestre de retração e um segundo semestre de recuperação da atividade econômica, e tal diferença importa para os propósitos deste trabalho.

${ }^{4}$ Deve-se fazer a ressalva que a metodologia de cálculo do desemprego não é a mesma em todos os países, o que, no entanto, não impede que sejam feitas considerações sobre sua tendência temporal.

${ }^{5} \mathrm{O}$ teste $\mathrm{t}$ rejeita, a $1 \%$, a hipótese de que o coeficiente B1 de homens seja igual ao de mulheres. $O$ mesmo vale para $\mathrm{B} 2$.

${ }^{6}$ Ainda que não se possa desprezar a possibilidade de que a crise do subprime, pelas suas proporções, tenha induzido ao aumento do desalento, esse fator deve ter sido modesto graças à curta duração da crise.
${ }^{7}$ Neste artigo, a indústria compreende três segmentos:

(i) indústria de transformação;

(ii) indústria extrativa; (iii) serviços industriais de utilidade pública (SIUP), que compreende a captação, o tratamento e a distribuição de água e produção e distribuição de eletricidade, gás e água. 


\section{Referências bibliográficas}

BANCO CENTRAL DO BRASIL. Relatório de Inflação, p. 28-30, set. 2006.

BANCO CENTRAL DO BRASIL. Desemprego aberto no Brasil: Contribuições da oferta e da demanda por trabalho. In: Relatório de Inflação, p. 17-19, dez. 2010.

CACCIAMALI, M. C.; TATEI, F. Crise econômica mundial: Mudança nas características do desemprego no mercado de trabalho? In: MORETTO, A.; KREIN, J. D.; POCHMANN, M.; MACAMBIRA, J. (Orgs.). Economia, desenvolvimento regional e mercado de trabalho no Brasil. Fortaleza-CE: IDT; BNB; Cesit, 2010. p. 53-78.

EICHENGREEN, B. The financial crises and global policy reforms. Paper for the Federal Reserve Bank of San Francisco conference on Asia and the financial crisis. Santa Barbara, California, 2009.

HOFFMAN, R.; LEONE, E. T. Participação da mulher no mercado de trabalho e desigualdade da renda domiciliar per capita no Brasil: 1981-2002. Nova Economia, v. 14, n. 2, p. 35-58, 2004.

\author{
INTERNATIONAL LABOUR \\ OFFICE. Recovery and growth with \\ decent work. 99th Session. Report \\ of the Director-General. \\ Geneva, 2010.
}

\section{INTERNATIONAL LABOUR} OFFICE. Global employment trends. The challenge of a jobs recovery. Geneva, 2011.

KRUGMAN, P. A crise de 2008 e a economia da depressão. Rio de Janeiro: Campos, 2009.

LEONE, E. T.; BALTAR, P. A mulher na recuperação recente do mercado de trabalho brasileiro. Revista Brasileira de Estudos Populacionais, v. 25, n. 2. p. 233-249, 2008.

MORETTO, A.; PRONI, M. W. O desemprego no Brasil: Análise da trajetória recente. Economia e Desenvolvimento, Recife (PE), v. 10, n. 1, p. 7-35, 2011.

POCHMANN, M. O trabalho na crise econômica no Brasil: Primeiros sinais. Estudos Avançados, v. 23, n. 66, p. 41-52, 2009.

RAMOS, L. Desempenho recente do mercado de trabalho brasileiro: 1992-2005. Revista de Economia Política, v. 29, n. 4 . p. 406-420, 2009.

REINHART C. M. \& ROGOFF, K. S. This time is different: Eight centuries of financial folly. Princeton: Princeton University Press, 2009.
SILVA, F. J. F. Perfil dos demitidos durante a crise de 2008 no Brasil. In: ENCONTRO NACIONAL DE ESTUDOS POPULACIONAIS: transformações na população brasileira: complexidades, incertezas e perspectivas, 18 ., 2012, Águas de Lindóia. Anais... Águas de Lindóia, ABEP, 2012.

STIGLITZ, J. E. The financial crisis of 2007/2008 and its macroeconomic consequences, meeting of the initiative for policy dialogue task force meeting on Financial Markets Reform, June. 2008.

STIGLITZ, J. E. The current economic crisis and lessons for economic theory. Eastern Economic Journal, v. 35, n. 3. p. 281-295, 2009.
E-mail de contato dos autores:

fabio.silva@bcb.gov.br

fernando.fonseca@bcb.gov.br

Artigo recebido em outubro de 2011 aprovado em fevereiro de 2013. 
Os empregos formais gerados ou o saldo mensal líquido de criação de emprego corresponde à diferença entre admissões e desligamento de empregos, segundo os dados do Cadastro Geral de Empregados e Desempregados (CAGED), instituído inicialmente como Cadastro Geral de Admissão e Dispensa, pela Lei $n^{\circ} 4.923$, de dezembro de 1965, e atualizado pela Portaria $\mathrm{n}^{\circ} 194$, de fevereiro de 1995 , com a finalidade de instrumentar as políticas de emprego do Ministério do Trabalho e Emprego.

Todos os empregadores sujeitos ao regime celetista de contratação de trabalho devem prestar as informações. As informações do CAGED são fornecidas mensalmente por meio magnético ou pela internet, pelos empregadores que têm empregados sob regime de trabalho celetista e que tiveram alguma movimentação de pessoal no mês, isto é, admissão, desligamento ou transferência. A declaração mensal dos estabelecimentos é feita até o dia 7 do mês subsequente ao da ocorrência da movimentação.

O Nível do Índice de Emprego Formal (NIEF) é calculado com base fixa no mês $t$ em relação ao mês anterior $(\mathrm{t}-1=100)$, de acordo com a seguinte fórmula:

$$
\mathrm{I}(\mathrm{t}, \mathrm{t}-1)=[\mathrm{EU}(\mathrm{t}) \mathrm{x} 100] /[\mathrm{E} 1(\mathrm{t})]
$$

onde: $\mathrm{I}(\mathrm{t}, \mathrm{t}-1)=$ índice mensal de emprego no mês $\mathrm{t}$ em relação ao mês anterior $(\mathrm{t}-1), \mathrm{EU}(\mathrm{t})=$ total de empregos ocupados no último dia do mês $\mathrm{t}, \mathrm{E} 1(\mathrm{t})=$ total de empregos ocupados no $1^{\circ}$ dia do mês t.

O cálculo assume a hipótese de que o total de empregos no último dia do mês t seja igual ao total de empregos no $1^{\circ}$ dia do mês $\mathrm{t}$ - 1. As informações são discriminadas considerando as atividades econômicas e por nível geográfico (regiões, respectivos estados, regiões metropolitanas e municípios) 
Anexo 2

\begin{tabular}{|c|c|c|c|}
\hline Atividades industriais & $\begin{array}{l}\text { Empregos totais } \\
\text { antes da crise } \\
\text { [em mil] } \\
\text { (a) }\end{array}$ & $\begin{array}{l}\text { Variação absoluta dos postos } \\
\text { de trabalho na crise } \\
\text { (em mil) } \\
\text { (b) }\end{array}$ & $\begin{array}{l}\text { Variação percentual dos } \\
\text { postos de trabalho na crise } \\
=\frac{b}{a}\end{array}$ \\
\hline Industria & $3.620,5$ & $-154,2$ & $-4,3 \%$ \\
\hline Indústria de transformação & $3.488,5$ & $-159,0$ & $-4,6 \%$ \\
\hline Produtos de metal & 356,6 & $-52,8$ & $-14,8 \%$ \\
\hline Vestuário & 452,2 & $-35,1$ & $-7,8 \%$ \\
\hline Alimentação e bebidas & 434,0 & $-28,5$ & $-6,6 \%$ \\
\hline Fabricaç̧ão de veículos & 320,9 & $-25,1$ & $-7,8 \%$ \\
\hline Metalurgia básica & 92,5 & $-17,3$ & $-18,7 \%$ \\
\hline Preparação de couros e calçados & 148,7 & $-16,2$ & $-10,9 \%$ \\
\hline $\begin{array}{l}\text { Fabricação de equipamentos de instrumentação } \\
\text { médico-hospitalares, instrumento de precisão e } \\
\text { ópticos, equipamentos para automação industrial }\end{array}$ & 53,7 & $-6,7$ & $-12,4 \%$ \\
\hline Outros & $1.630,0$ & 22,7 & $1,4 \%$ \\
\hline Indústria Extrativa & 43,5 & 2,8 & $6,4 \%$ \\
\hline Serv. Industriais de Utilidade Pública (SIUP) & 88,5 & 2,0 & 2,3\% \\
\hline
\end{tabular}

Fonte: Elaboração dos autores com os dados da PME/IBGE. 
